\title{
Characterization and speciation of mercury in mosses and lichens from the high-altitude Tibetan Plateau
}

\author{
Jun-juan Shao $\cdot$ Cheng-bin Liu $\cdot$ Qing-hua Zhang $\cdot$ Jian-jie Fu \\ Rui-qiang Yang $\cdot$ Jian-bo Shi $\mathbb{D} \cdot$ Yong Cai $\cdot$ Gui-bin Jiang
}

Received: 2 February 2015/Accepted: 26 April 2016/Published online: 3 May 2016

(C) Springer Science+Business Media Dordrecht 2016

\begin{abstract}
The accumulation and species of mercury $(\mathrm{Hg})$ in mosses and lichens collected from highaltitude Tibetan Plateau were studied. The altitudes of the sampling sites spanned from 1983 to $5147 \mathrm{~m}$, and a total of 130 mosses and 52 lichens were analyzed. The total mercury (THg) contents in mosses and lichens were in the ranges of $13.1-273.0$ and $20.2-345.9 \mathrm{ng} / \mathrm{g}$, respectively. The average ratios of methylmercury $(\mathrm{MeHg})$ in $\mathrm{THg}$ in mosses and lichens were $2.4 \%$ $(0.3-11.1 \%)$ and $2.7 \%(0.4-9.6 \%)$, respectively, which were higher than those values reported in other regions. The contents of $\mathrm{THg}$ in both mosses and lichens were not correlated with the $\mathrm{THg}$ in soils $(p>0.05)$. The lipid contents displayed a significantly positive correlation with concentrations of $\mathrm{MeHg}$ in mosses $(r=0.461, p<0.01, n=90)$, but not in lichens. The correlations between $\mathrm{Hg}$ contents in
\end{abstract}

J. Shao - C. Liu - Q. Zhang · J. Fu · R. Yang ·

J. Shi $(\bowtie)$. Y. Cai · G. Jiang

State Key Laboratory of Environmental Chemistry and Ecotoxicology, Research Center for Eco-Environmental

Sciences, Chinese Academy of Sciences, Beijing 100085,

China

e-mail: jbshi@rcees.ac.cn

J. Shi · Y. Cai

Institute of Environment and Health, Jianghan University, Wuhan 430056, China

J. Shao $\cdot$ C. Liu · G. Jiang

College of Resources and Environment, University of Chinese Academy of Sciences, Beijing 100049, China mosses and the altitudes, latitudes and longitudes of sampling sites indicated the mountain trapping and spatial deposition of $\mathrm{Hg}$ in the Tibetan Plateau.

Keywords Moss · Lichen · Mercury · Methylmercury · Tibetan Plateau

\section{Introduction}

As a global pollutant, mercury $(\mathrm{Hg})$ has the characteristics of persistence, bioaccumulation and toxicity (PBT). Elemental $\mathrm{Hg}$ has low vapor pressure and long residence time (0.5-2 years) in the atmosphere. Once emitted in the environment, $\mathrm{Hg}$ can undergo long-range transport and deposit to remote ecosystem (Fitzgerald et al. 1998; Miller et al. 2005) even in polar regions (Bargagli et al. 2005, 2007; Negri et al. 2006; Poissant et al. 2008) and high mountain areas. Due to their special geographic positions and environmental conditions, studying the cycling of $\mathrm{Hg}$ in remote or high-altitude regions is indispensable for understanding the global transport of $\mathrm{Hg}$.

The Tibetan Plateau, located in the north of the Himalayas, is one of the most remote and high-altitude regions in the world. It is also called the "roof of the world" (with an average elevation of $4000 \mathrm{~m}$ above sea level) and one of the "three polar regions" (together with the Arctic and the Antarctic). Although 
there is little industry, relatively high levels of persistent organic pollutants (POPs) and heavy metals have been detected in various environmental matrices due to the mountain trapping effect in this highaltitude region (Sheng et al. 2013; Wang et al. 2014; Yang, et al. 2007, 2013). Therefore, Tibetan is an ideal site for studying the long-range atmospheric transport of semi-volatile pollutants (Cong et al. 2007).

Recently, unexpectedly high concentrations of $\mathrm{Hg}$ were also found in fish collected from Tibetan Plateau (Shao et al. 2016; Yang et al. 2011; Zhang et al. 2014). However, the studies are still limited, and fish can only reflect the contamination status in several specific aquatic ecosystems. For water and atmosphere, the low contents of $\mathrm{Hg}$ and the difficulties in sampling, preservation and detection make them not appropriate for a large-scale study. Up to now, neither accumulation nor $\mathrm{Hg}$ species in other biological samples from the Tibetan Plateau have been reported, which are imperative for further understanding the biogeochemical cycle of $\mathrm{Hg}$ in this typical region.

Mosses and lichens are geographically widespread and can grow even in cold and high-altitude mountain regions including the Tibetan Plateau. Because they have enough abundance and wide distribution for repetitive sampling and comparison and can accumulate high levels of pollutants exceeding their metabolic requirements (Backor and Loppi 2009), mosses and lichens are ideal samples to study the contamination in typical regions, where large-scale sampling is difficult and expensive. As mosses and lichens do not have roots, they absorb most nutrients from the atmosphere and take up negligible amounts of water and minerals from soil. This makes both biota more suitable for indicating the source and sink of atmospheric pollutants, including $\mathrm{Hg}$ (Bargagli et al. 2002; Bergamaschi et al. 2002; Onianwa 2001; Sardans and Penuelas 2005; Schintu et al. 2005; Vannini et al. 2014; Zechmeister et al. 2003).

The aims of this work were to study the accumulation and species of $\mathrm{Hg}$ in mosses and lichens collected from the Tibetan Plateau and their implications for indicating related deposition of $\mathrm{Hg}$. The altitude of the sampling sites spanned from 1983 to $5147 \mathrm{~m}$, and corresponding soil samples were also investigated. To our knowledge, this is the first largescale studying $\mathrm{Hg}$ accumulation in vegetation samples from Tibet and provides a basis for further study of $\mathrm{Hg}$ contamination in this high-altitude region.

\section{Materials and methods}

Sample collection

A map of the study area and the sampling sites are shown in Fig. 1. A total of 130 mosses (Bryopsida), 52 lichens (Usnealongissima Ach.) and 146 soil samples were collected from 160 sites of the Tibetan Plateau in June of 2010, 2011 and 2012. At each site, samples were collected using a stainless steel spade. Surface soil samples were collected in the depth of $0-5 \mathrm{~cm}$. All samples were sealed in clean polyethylene bags and carried back to the laboratory immediately. The green shoots of mosses and the outermost portion of the lichens were kept and rinsed with deionized water before pretreatment. All samples were freeze-dried, ground and then kept at $-20{ }^{\circ} \mathrm{C}$ until analysis. In addition, the soil samples were passed through a 100-mesh sieve.

Determination of total mercury (THg), methylmercury $(\mathrm{MeHg})$ and lipid contents

Using a Hydra II-C atomic absorption spectrometer (Teledyne Leeman Labs, Hudson, USA), the contents of THg in solid samples could be automatically burned and determined without further pretreatment. For soil samples, about $0.25 \mathrm{~g}$ ground sample was weighed in a nickel boat and then analyzed directly. For mosses and lichens, about $0.05 \mathrm{~g}$ sample was weighed because the relatively high lipid content may cause matrix effects.

For $\mathrm{MeHg}$ analysis, about $0.2 \mathrm{~g}$ sample was weighed into an $8-\mathrm{mL}$ brown glass tube and $2 \mathrm{~mL}$ $25 \%(\mathrm{~m} / \mathrm{v}) \mathrm{KOH} / \mathrm{CH}_{3} \mathrm{OH}$ solution was added. The mixture was mechanically shaken for $4 \mathrm{~h}$ at $37^{\circ} \mathrm{C}$ and $240 \mathrm{rpm}$. After cooling down, the solution was centrifuged at $3000 \mathrm{rpm}$ for $20 \mathrm{~min}$. Then, $0.15 \mathrm{~mL}$ of solution was transferred into the autosampler vial and ethylated by sodium tetraethyl borate $\left(\mathrm{NaBEt}_{4}\right)$. The concentration of $\mathrm{MeHg}$ was determined by purge and trap gas chromatography-atomic fluorescence spectrometry (GC-AFS) method with a MERX Automatic Methylmercury System (Brooks Rand Laboratories, Seattle, WA). The concentrations of inorganic mercury $(\mathrm{IHg}$ ) were calculated by subtracting the contents of $\mathrm{MeHg}$ from $\mathrm{THg}$.

The lipid contents of mosses and lichens were determined gravimetrically. Two grams mosses or lichens and $10 \mathrm{~g}$ anhydrous sodium sulfate were 
Fig. 1 Map of the study area

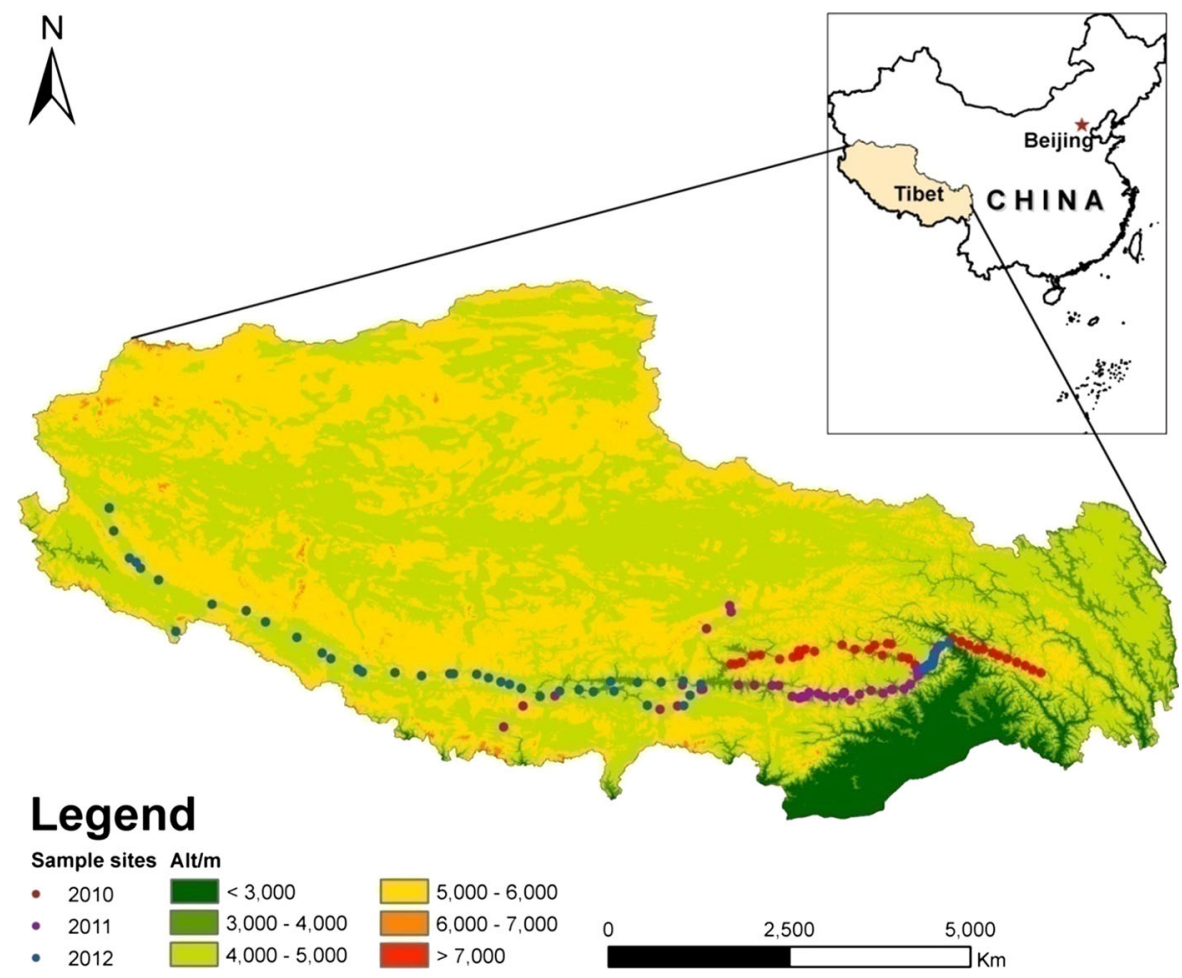

Table 1 Results of $\mathrm{THg}$ and $\mathrm{MeHg}$ in certified reference materials (CRMs) $(\mathrm{ng} / \mathrm{g}, n=5$ )

\begin{tabular}{|c|c|c|c|c|c|c|}
\hline \multirow[t]{2}{*}{ CRMs } & \multicolumn{3}{|l|}{$\mathrm{THg}$} & \multicolumn{3}{|l|}{$\mathrm{MeHg}$} \\
\hline & Certified & Determined & Recovery (\%) & Certified & Determined & Recovery (\%) \\
\hline GBW07312 (sediment) & $56 \pm 6$ & $54.7 \pm 1.8$ & $97.7 \pm 3.2$ & - & - & - \\
\hline GBW10020 (citrus leaf) & $150 \pm 20$ & $149.8 \pm 2.8$ & $99.9 \pm 1.9$ & - & - & - \\
\hline TORT-2 (lobster) & $270 \pm 60$ & $263.0 \pm 15.0$ & $97.4 \pm 5.6$ & $152 \pm 13$ & $169.9 \pm 4.2$ & $111.8 \pm 2.8$ \\
\hline DORM-4 (fish) & $410 \pm 55$ & $373.2 \pm 2.0$ & $91.0 \pm 0.5$ & $354 \pm 31$ & $335.3 \pm 11.7$ & $94.7 \pm 3.3$ \\
\hline
\end{tabular}

extracted using mixed solvents of hexane and dichloromethane $(1: 1, \mathrm{v} / \mathrm{v})$ by accelerated solvent extraction (Dionex ASE 300, USA) at a temperature of $120{ }^{\circ} \mathrm{C}$ and a pressure of 1200 psi. The equilibration time was $10 \mathrm{~min}$, and the extractions were performed for 3 cycles. The extraction was transferred into a clean and dry round-bottom flask $\left(m_{1}\right)$ and subsequently concentrated on a rotary evaporator and with a high-purity nitrogen stream. The round-bottom flask was left overnight until constant weight and then weighted $\left(m_{2}\right)$. The lipid content was calculated with the following equation (Stacl and Ronald 1994):

The lipid content $=\left(m_{2}-m_{1}\right) / m_{\text {sample }}$
Quality assurance/quality control (QA/QC)

For the analytical quality control, reagent blanks, certified reference materials (CRMs) and samples replicates were inserted in the analysis at set intervals. The analyzed values were in good agreement with the certified values (Table 1). Due to lack of plant CRMs for $\mathrm{MeHg}, 0.2 \mathrm{~mL}$ of $1 \mathrm{ng} / \mathrm{mL} \mathrm{MeHg}$ standard solutions was spiked into the moss and lichen samples before extraction and the spiked recoveries of the entire method were between 85 and $107 \%$, indicating the accuracy of the method. The reproducibility of the spiked recoveries was also satisfied. 
Statistical analysis

In order to extract information from the chemical analysis, multiple statistical analyses were performed with SPSS 20.0. A test of normality was executed to check the normal distribution of the analytical data. Under the premise of lacking of normality, Spearman's correlation was used for correlation analysis. Independent samples test and paired samples test were applied to assess the significant difference in comparisons.

\section{Results and discussion}

THg and MeHg in mosses, lichens and soils

The concentrations of $\mathrm{THg}$ in moss, lichen and soil samples were in the range of 13.1-273.0 ng/g (average: $53.5 \mathrm{ng} / \mathrm{g}$ ), $20.2-345.9 \mathrm{ng} / \mathrm{g}$ (average: $77.7 \mathrm{ng} / \mathrm{g}$ ) and 5.6-388.2 ng/g (average: $42.3 \mathrm{ng} / \mathrm{g}$ ), respectively. As a whole, the contents of $\mathrm{THg}$ in mosses and soils from Tibet were in the same order of magnitude with those from the Antarctica and the Arctic, while the $\mathrm{THg}$ in lichens were much lower than those from the Antarctic (Table 2). The average content of $\mathrm{Hg}$ in the Earth's crust was about $50 \mathrm{ng} / \mathrm{g}$ dry wt (Bargagli et al. 2005, 2007). According to the results investigated by the China National Environmental Monitoring Center in 1980s, the China national average concentration of $\mathrm{Hg}$ in topsoil was $0.065 \mathrm{mg} / \mathrm{kg}$ (range 0.001-45.9 mg/ $\mathrm{kg}$ ) (Wei et al. 1991). Several recent studies showed that the average concentration of $\mathrm{Hg}$ in soils from the Tibetan Plateau was 26 ng/g (Table 2) (Zhang 1994; Zhang et al. 2002; Zhu et al. 2014). Compared with these results, the average concentration of $\mathrm{Hg}$ in soils collected in this work was still in a relatively low level.

The concentrations of MeHg in mosses and lichens were in the range of $0.1-6.1 \mathrm{ng} / \mathrm{g}$ (average: $1.1 \mathrm{ng} / \mathrm{g}$ ) and $0.3-5.5 \mathrm{ng} / \mathrm{g}$ (average: $1.5 \mathrm{ng} / \mathrm{g}$ ), respectively. The MeHg contents were positively correlated with $\mathrm{THg}$ concentrations both in mosses $(r=0.505$, $p<0.01, n=130)$ and in lichens $(r=0.342$, $p<0.05, n=52$ ). The mean ratios of $\mathrm{MeHg}$ in $\mathrm{THg}$ in mosses and lichens were $2.4 \%(0.3-11.1 \%)$ and $2.7 \%(0.4-9.6 \%)$, respectively, which were higher than those reported values in mosses and lichens from other regions (Hall and Louis 2004; Lupsina et al. 1992). This is probably because ultraviolet (UV)

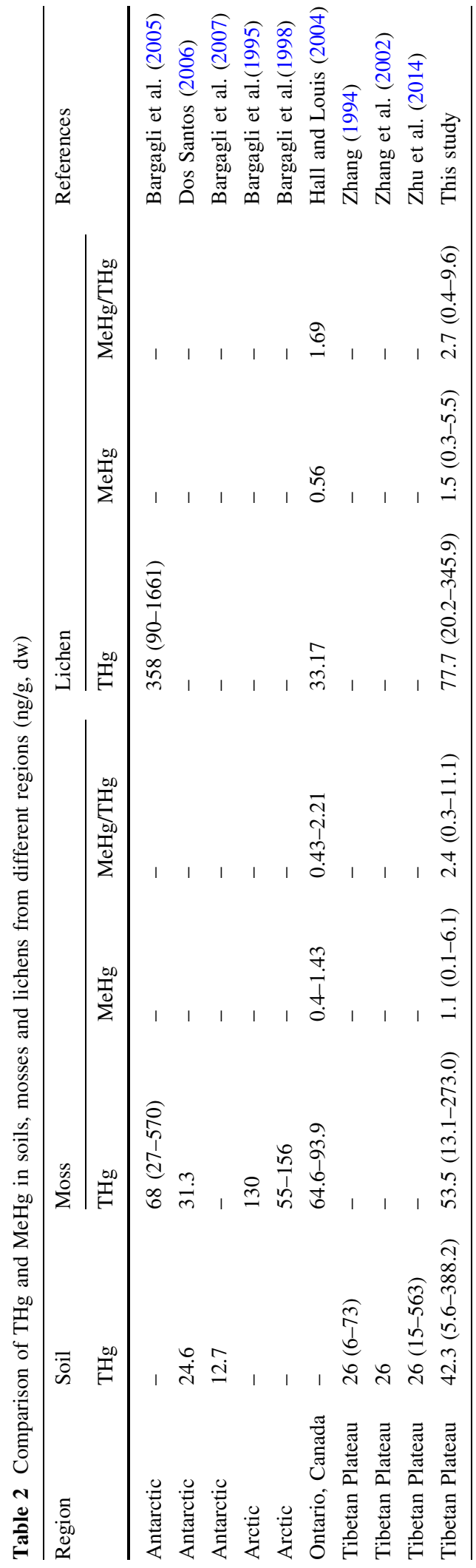


radiation increases with altitudes (Dahlback et al. 2007) and the UV radiation in the high-altitude Tibet is relatively strong (Ren et al. 1997), which can oxidize gaseous elemental $\mathrm{Hg}$ to divalent reactive gaseous mercury more easily and accelerate the methylation of gaseous elemental Hg (Lalonde et al. 2001). This has been demonstrated in surface water of lakes in Kejimkujik, Canada, where the concentration of $\mathrm{MeHg}$ was the highest in the early afternoon because the UV light was the strongest at that time (Siciliano et al. 2005). As a result, the mosses and lichens in Tibet may accumulate relatively high ratio of $\mathrm{MeHg}$.

Factors affecting $\mathrm{Hg}$ accumulation in mosses and lichens

In order to find the factors affecting $\mathrm{Hg}$ accumulation in mosses and lichens, soil samples from the same sites were also collected and analyzed. As shown in Table 2, the concentrations of $\mathrm{THg}$ in soils ranged from $5.6 \mathrm{ng} / \mathrm{g}$ to 388.2. However, the $\mathrm{THg}$ contents in mosses and lichens were not correlated with the $\mathrm{THg}$ in soils $(p>0.05)$, demonstrating that the soil is not the main source of $\mathrm{Hg}$ in mosses and lichens. This could be explained by mosses and lichens absorbing most nutrients from the atmosphere instead of the soils and agrees with previous studies (Bargagli et al. 2002; Onianwa 2001; Sardans and Penuelas 2005; Schintu et al. 2005; Zechmeister et al. 2003).

Because of the lipophilicity of $\mathrm{MeHg}$, it accumulates generally easier in higher lipid organisms. The contents of lipid in mosses and lichens were in the range of 0.48-7.21\% (average: $2.90 \%$ ) and 3.33-32.74\% (average: $14.49 \%$ ). Unexpectedly, the concentrations of $\mathrm{MeHg}$ in lichens were not correlated with the lipid contents $(r=-0.084, p>0.05, n=48)$, although they contained more lipid than mosses. On the contrary, the concentrations of $\mathrm{MeHg}$ displayed a significantly positive correlation with lipid contents in mosses ( $r=0.461, p<0.01, n=90)$. In addition, the THg and $\mathrm{IHg}$ contents in both mosses and lichens showed no significant correlation with the lipid contents $(p>0.05)$.

The spatial distribution of $\mathrm{THg}, \mathrm{MeHg}$ and $\mathrm{IHg}$ in mosses

Because the collected lichens were anchored on barks or twigs, the spatial distribution of lichens and available sampling sites in the Tibet are limited.
Therefore, correlations between $\mathrm{THg}, \mathrm{MeHg}$ and $\mathrm{IHg}$ in lichens and altitudes, longitudes and latitudes of the sampling sites were not statistically analyzed. Only the correlations between these parameters of sampling sites and $\mathrm{Hg}$ in mosses were further investigated.

In high mountain regions, altitude is an important factor influencing the distribution of $\mathrm{Hg}$ due to the mountain trapping (Zhang et al. 2013). In this work, all the concentrations of THg $(r=0.362, p<0.01$, $n=130), \mathrm{MeHg}(r=0.281, p<0.01, n=130)$ and $\mathrm{IHg}(r=0.378, p<0.01, n=130)$ in mosses showed significantly positive correlations with the altitudes of sampling sites (Table 3; Fig. 2). The increasing rates of concentrations along with altitudes were $1.52,1.07$ and $1.49 \mathrm{ng} / \mathrm{g}$ per $100 \mathrm{~m}$ for $\mathrm{THg}$, $\mathrm{MeHg}$ and $\mathrm{IHg}$ in mosses. This could be attributed to the mountain trapping effect of $\mathrm{Hg}$ and was in agreement with other studies (Zhang et al. 2013). Normally, $\mathrm{Hg}$ can undergo long-range atmospheric transport and be deposited to remote places and highaltitude mountainous areas. The more frequent precipitation in higher elevations would result in greater $\mathrm{Hg}$ wet deposition. Thus, the concentrations of $\mathrm{THg}$, $\mathrm{MeHg}$ and $\mathrm{IHg}$ in mosses increased with the increasing altitudes of the sampling sites.

The concentrations of $\mathrm{THg}, \mathrm{MeHg}$ and $\mathrm{IHg}$ in mosses displayed a significantly negative correlation with the longitudes of the sampling sites (for THg, $r=-0.489$, $p<0.01, n=130$; for MeHg, $r=-0.495, p<0.01$, $n=130$; for $\mathrm{IHg}, r=-0.479, p<0.01, n=130$ ) (Table 3). This suggested that the contents of $\mathrm{THg}$, $\mathrm{MeHg}$ and $\mathrm{IHg}$ in mosses decreased from west to east, which were consistent with the distribution pattern of organochlorine pesticides (OCPs) (Yang et al. 2013) and heavy metals (Cong et al. 2007), indicating the atmospheric transport of $\mathrm{Hg}$ to Tibet.

The correlations between the latitudes of the sampling sites and the concentrations of $\mathrm{THg}, \mathrm{MeHg}$ and $\mathrm{IHg}$ in mosses were also investigated. The latitudes showed little effects on the $\mathrm{THg}$ and $\mathrm{IHg}$ concentrations in mosses $(p>0.05)$, probably because of the relatively smaller range of latitudes of the sampling sites $\left(\mathrm{N} 28.5160^{\circ}-31.1409^{\circ}\right)$. We also noticed that the $\mathrm{MeHg}$ contents in mosses showed a significantly negative correlation with the latitudes of the sampling sites ( $r=-0.308, p<0.01, n=130)$. Because the factors regulating the distribution of $\mathrm{MeHg}$ in mosses are complex, further studies are needed to explain this correlation. 
Table 3 Correlations of $\mathrm{THg}, \mathrm{MeHg}$ and $\mathrm{IHg}$ contents in mosses with the lipid, altitude, longitude and latitude

\begin{tabular}{lrrr}
\hline & \multicolumn{1}{l}{$\mathrm{THg}$} & $\mathrm{MeHg}$ & $\mathrm{IHg}$ \\
\hline Lipid & $-0.09(n=90)$ & $0.392^{* *}(n=90)$ & $-0.109(n=90)$ \\
Altitude & $0.362^{* *}(n=130)$ & $0.281^{* *}(n=130)$ & $0.378^{* *}(n=130)$ \\
Longitude & $-0.489 * *(n=130)$ & $-0.495 * *(n=130)$ & $-0.479 * *(n=130)$ \\
Latitude & $-0.124(n=130)$ & $-0.308^{* *}(n=130)$ & $-0.116(n=130)$ \\
\hline
\end{tabular}

** Correlation is significant at the 0.01 level (two-tailed)

* Correlation is significant at the 0.05 level (two-tailed)
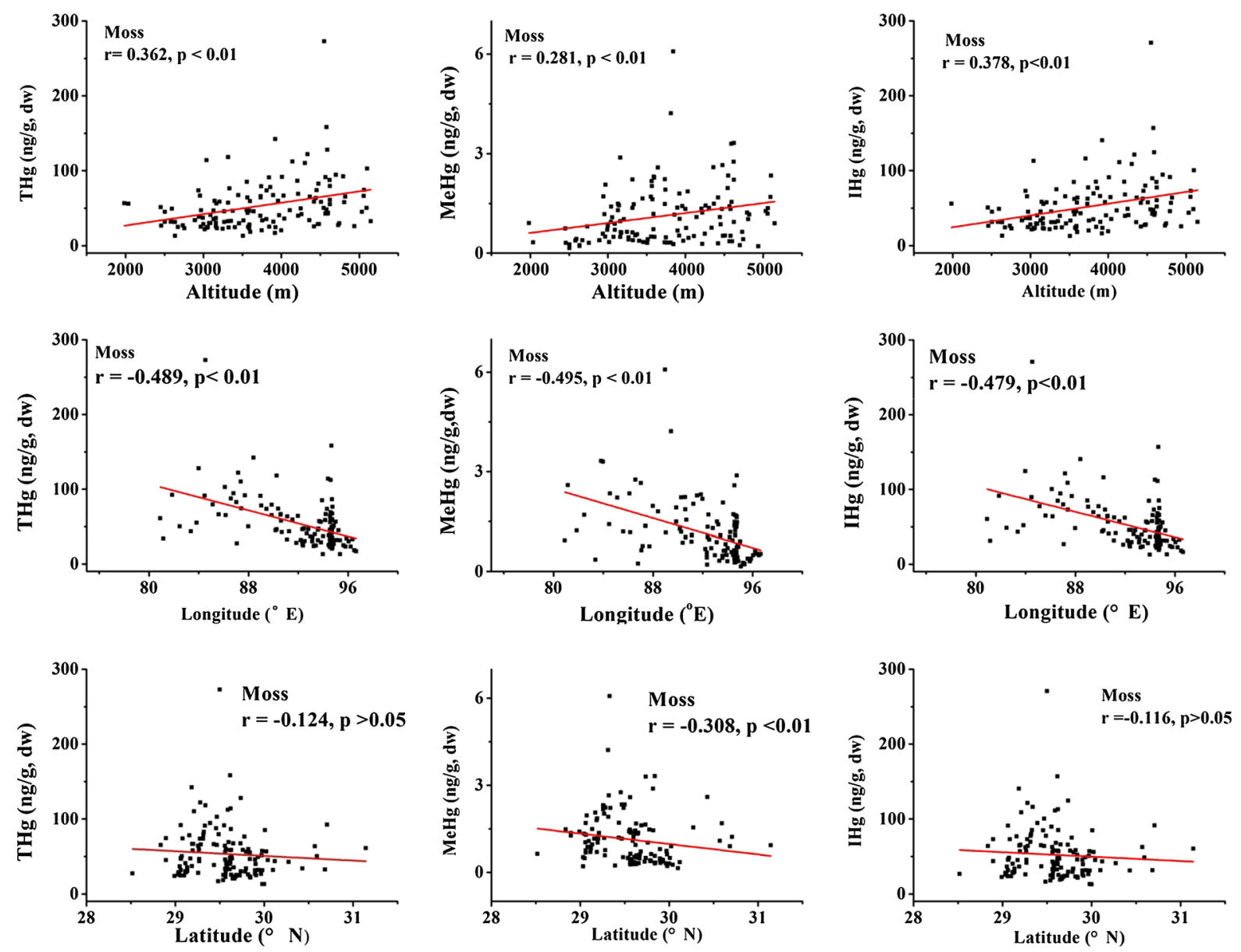

Fig. 2 Spatial distributions of $\mathrm{THg}, \mathrm{MeHg}$ and $\mathrm{IHg}$ in mosses

Environmental implications

As the "roof of the world," Tibet is an ideal and indispensable area for studying the long-range atmospheric transport of $\mathrm{Hg}$. However, due to the extremely harsh environmental conditions and the difficulties in sampling, the large-scale study about the biogeochemical cycle of $\mathrm{Hg}$ in this high-altitude and mountainous region is difficult.

As a scientific and effective approach, bioindication has been widely applied for assessing the contamination and toxic effects of $\mathrm{Hg}$ and other 
pollutants in the environment (Vannini et al. 2014; Zhou et al. 2008). By analyzing appropriate bioindicators, the high cost and difficulties in sampling could be avoided for studying $\mathrm{Hg}$ pollution in harsh environments. Some organisms have been successfully used for $\mathrm{Hg}$ bioindication, such as macroalgae (Cairrao et al. 2007), oyster (Vaisman et al. 2005), Halimione portulacoides (Válega et al. 2008) and mussel (Blackwell et al. 2013). However, the use of these indicators is impracticable for studying the environmental behavior of $\mathrm{Hg}$ in Tibet.

Mosses and lichens are geographically widespread and can grow even in cold and high-altitude regions including Tibetan Plateau. They have also been suggested to be used as bioindicators of $\mathrm{Hg}$ (Bargagli et al. 2005, 2007; Bergamaschi et al. 2002). In this work, the contents of $\mathrm{THg}, \mathrm{MeHg}$ and $\mathrm{IHg}$ in mosses reflected the geographic variations and the mountain trapping of $\mathrm{Hg}$ in the high-altitude Tibetan Plateau, indicating the potential application of moss as bioindicator of $\mathrm{Hg}$ in the Tibetan Plateau. However, the species is an important factor influencing the accumulation of $\mathrm{Hg}$ in moss due to the different metabolic and morphological characteristics of various moss species (Bargagli et al. 2002; Onianwa 2001; Vannini et al. 2014). In this work, the altitude of the sampling sites spanned from 1983 to $5147 \mathrm{~m}$ and it is difficult to ensure a single species in all sampling sites. Thus, the collected mosses were not differentiated at the species level. In addition, the mechanism and processes of $\mathrm{Hg}$ accumulation in moss are complicated and much still remain unknown. Further studies are necessary to be done in the future.

\section{Conclusions}

Due to the special geographic position and the environmental conditions, the accumulation and biogeochemical cycling of $\mathrm{Hg}$ in Tibetan Plateau may differ from other regions, which is indispensable for understanding the long-range transport of $\mathrm{Hg}$. The contents of THg in both mosses and lichens were not correlated with the $\mathrm{THg}$ in soils $(p>0.05)$. The lipid contents displayed a significantly positive correlation with concentrations of $\mathrm{MeHg}$ in mosses $(r=0.461, p<0.01, n=90)$, but not in lichens. Meanwhile, the contents of $\mathrm{THg}$, $\mathrm{MeHg}$ and $\mathrm{IHg}$ in mosses reflected the geographic variations and the mountain trapping of $\mathrm{Hg}$ in the high-altitude Tibetan Plateau.

Acknowledgments The work described here was supported by the National Basic Research Program of China (2013CB430004), the National Natural Science Foundation of China (41422306 and 21120102040) and the Young Scientists Fund of RCEES (RCEES-QN-20130007F).

\section{References}

Backor, M., \& Loppi, S. (2009). Interactions of lichens with heavy metals. Biologia Plantarum, 53(2), 214-222.

Bargagli, R., Brown, D. H., \& Nelli, L. (1995). Metal biomonitoring with mosses: Procedures for correcting for soil contamination. Environmental Pollution, 89(2), 169-175.

Bargagli, R., Sanchez-Hernandez, J. C., Martella, L., \& Monaci, F. (1998). Mercury, cadmium and lead accumulation in Antarctic mosses growing along nutrient and moisture gradients. Polar Biology, 19(5), 316-322.

Bargagli, R., Agnorelli, C., Borghini, F., \& Monaci, F. (2005). Enhanced deposition and bioaccumulation of mercury in Antarctic terrestrial ecosystems facing a coastal polynya. Environmental Science and Technology, 39(21), 8150-8155.

Bargagli, R., Monaci, F., Borghini, F., Bravi, F., \& Agnorelli, C. (2002). Mosses and lichens as biomonitors of trace metals. A comparison study on Hypnum cupressiforme and Parmelia caperata in a former mining district in Italy. Environmental Pollution, 116(2), 279-287.

Bargagli, R., Monaci, F., \& Bucci, C. (2007). Environmental biogeochemistry of mercury in Antarctic ecosystems. Soil Biology \& Biochemistry, 39(1), 352-360.

Bergamaschi, L., Rizzio, E., Valcuvia, M. G., Verza, G., Profumo, A., \& Gallorini, M. (2002). Determination of trace elements and evaluation of their enrichment factors in Himalayan lichens. Environmental Pollution, 120(1), 137-144.

Blackwell, B. D., Driscoll, C. T., Spada, M. E., Todorova, S. G., \& Montesdeoca, M. R. (2013). Evaluation of zebra mussels (Dreissena polymorpha) as biomonitors of mercury contamination in aquatic ecosystems. Environmental Toxicology and Chemistry, 32(3), 638-643.

Cairrao, E., Pereira, M. J., Pastorinho, M. R., Morgado, F., Soares, A. M. V. M., \& Guilhermino, L. (2007). Fucus spp. as a mercury contamination bioindicator in costal areas (Northwestern Portugal). Bulletin of Environmental Contamination and Toxicology, 79(4), 388-395.

Cong, Z. Y., Kang, S. C., Liu, X. D., \& Wang, G. F. (2007). Elemental composition of aerosol in the Nam Co region, Tibetan Plateau, during summer monsoon season. Atmospheric Environment, 41(6), 1180-1187.

Dahlback, A., Gelsor, N., Stamnes, J. J. \& Gjessing, Y. (2007). UV measurements in the $3000-5000 \mathrm{~m}$ altitude region in Tibet. Journal of Geophysical Research-Atmospheres, 112(D9).

dos Santos, I. R., Silva-Filho, E. V., Schaefer, C., Maria Sella, S., Silva, C. A., Gomes, V., Passos, M. J., \& Van Ngan, P. (2006). Baseline mercury and zinc concentrations in terrestrial and coastal organisms of Admiralty Bay, Antarctica. Environmental Pollution, 140(2), 304-311. 
Fitzgerald, W. F., Engstrom, D. R., Mason, R. P., \& Nater, E. A. (1998). The case for atmospheric mercury contamination in remote areas. Environmental Science and Technology, $32(1), 1-7$.

Hall, B. D., \& Louis, V. L. S. (2004). Methylmercury and total mercury in plant litter decomposing in upland forests and flooded landscapes. Environmental Science and Technology, 38(19), 5010-5021.

Lalonde, J. D., Amyot, M., Kraepiel, A. M. L., \& Morel, F. M. M. (2001). Photooxidation of $\operatorname{Hg}(0)$ in artificial and natural waters. Environmental Science and Technology, 35(7), 1367-1372.

Lupsina, V., Horvat, M., Jeran, Z., \& Stegnar, P. (1992). Investigation of mercury speciation in lichens. Analyst, 117(3), 673-675.

Miller, E., Vanarsdale, A., Keeler, G., Chalmers, A., Poissant, L., Kamman, N., \& Brulotte, R. (2005). Estimation and mapping of wet and dry mercury deposition across northeastern north America. Ecotoxicology, 14(1-2), 53-70.

Negri, A., Burns, K., Boyle, S., Brinkman, D., \& Webster, N. (2006). Contamination in sediments, bivalves and sponges of McMurdo Sound, Antarctica. Environmental Pollution, 143(3), 456-467.

Onianwa, P. C. (2001). Monitoring atmospheric metal pollution: A review of the use of mosses as indicators. Environmental Monitoring and Assessment, 71(1), 13-50.

Poissant, L., Zhang, H. H., Canário, J., \& Constant, P. (2008). Critical review of mercury fates and contamination in the arctic tundra ecosystem. Science of the Total Environment, 400(1-3), 173-211.

Ren, P. B. C., Sigernes, F., \& Gjessing, Y. (1997). Ground-based measurements of solar ultraviolet radiation in Tibet: Preliminary results. Geophysical Research Letters, 24(11), 1359-1362.

Sardans, J., \& Penuelas, J. (2005). Trace element accumulation in the moss Hypnum cupressiforme Hedw. and the trees Quercus ilex L. and Pinus halepensis Mill. in Catalonia. Chemosphere, 60(9), 1293-1307.

Schintu, M., Cogoni, A., Durante, L., Cantaluppi, C., \& Contu, A. (2005). Moss (Bryum radiculosum) as a bioindicator of trace metal deposition around an industrialised area in Sardinia (Italy). Chemosphere, 60(5), 610-618.

Shao, J. J., Shi, J. B., Duo, B., Liu, C. B., Gao, Y., Fu, J. J., et al. (2016). Mercury in alpine fish from four rivers in the Tibetan Plateau. Journal of Environmental Sciences, 39, 22-28.

Sheng, J. J., Wang, X. P., Gong, P., Joswiak, D. R., Tian, L., Yao, T. D., \& Jones, K. C. (2013). Monsoon-driven transport of organochlorine pesticides and Polychlorinated Biphenyls to the Tibetan Plateau: three year atmospheric monitoring study. Environmental Science and Technology, 47(7), 3199-3208.

Siciliano, S. D., O'Driscoll, N. J., Tordon, R., Hill, J., Beauchamp, S., \& Lean, D. R. S. (2005). Abiotic production of methylmercury by solar radiation. Environmental Science and Technology, 39(4), 1071-1077.

Stacl, L. S., \& Ronald, A. H. (1994). Vegetation-atmosphere partitioning of polycyclic aromatic hydrocarbons. Environmental Science and Technology, 28(5), 939-943.

Vaisman, A. G., Marins, R. V., \& Lacerda, L. D. (2005). Characterization of the mangrove oyster, Crassostrea rhizophorae, as a biomonitor for mercury in tropical estuarine systems, northeast Brazil. Bulletin of Environmental Contamination and Toxicology, 74(3), 582-588.

Válega, M., Lilleb $\varnothing$, A. I., Pereira, M. E., Caçador, I., Duarte, A. C., \& Pardal, M. A. (2008). Mercury in salt marshes ecosystems: Halimione portulacoides as biomonitor. Chemosphere, 73(8), 1224-1229.

Vannini, A., Nicolardi, V., Bargagli, R., \& Loppi, S. (2014). Estimating atmospheric mercury concentrations with lichens. Environmental Science and Technology, 48(15), 8754-8759.

Wang, X. P., Halsall, C., Codling, G., Xie, Z. Y., Xu, B. Q., Zhao, Z., et al. (2014). Accumulation of perfluoroalkyl compounds in Tibetan Mountain snow: Temporal patterns from 1980 to 2010. Environmental Science and Technology, 48(1), 173-181.

Wei, F. S., Chen, J. S., Wu, Y. Y., \& Zheng, C. J. (1991). Study on soil background values of China. Environ Sci, 12(4), 12-19. (in Chinese).

Yang, R. Q., Jing, C. Y., Zhang, Q. H., Wang, Z. H., Wang, Y. W., Li, Y. M., \& Jiang, G. B. (2011). Polybrominated diphenyl ethers (PBDEs) and mercury in fish from lakes of the Tibetan Plateau. Chemosphere, 83(6), 862-867.

Yang, R. Q., Yao, T. D., Xu, B. Q., Jiang, G. B., \& Xin, X. D. (2007). Accumulation features of organochlorine pesticides and heavy metals in fish from high mountain lakes and Lhasa River in the Tibetan Plateau. Environment International, 33(2), 151-156.

Yang, R. Q., Zhang, S. J., Li, A., Jiang, G. B., \& Jing, C. Y. (2013). Altitudinal and spatial signature of persistent organic pollutants in soil, lichen, conifer needles, and bark of the southeast Tibetan Plateau: Implications for sources and environmental cycling. Environmental Science and Technology, 47(22), 12736-12743.

Zechmeister, H. G., Hohenwallner, D., Riss, A., \& Hanus-Illnar, A. (2003). Variations in heavy metal concentrations in the moss species Abietinella abietina (Hedw.) Fleisch according to sampling time, within site variability and increase in biomass. Science of the Total Environment, 301(1-3), 55-65.

Zhang, X. P. (1994). Research on the environmental background values of soils in Xizang. Scientia Geographica Sinica, 14(1), 49-55.

Zhang, X. P., Deng, W., \& Yang, X. M. (2002). The background concentrations of 13 soil trace elements and their relationships to parent materials and vegetation in Xizang (Tibet), China. Journal of Asian Earth Sciences, 21, 167-174.

Zhang, Q. G., Pan, K., Kang, S. C., Zhu, A., \& Wang, W. X. (2014). Mercury in wild fish from high-altitude aquatic ecosystems in the Tibetan Plateau. Environmental Science and Technology, 48(9), 5220-5228.

Zhang, H., Yin, R. S., Feng, X. B., Sommar, J., Anderson, C. W. N., Sapkota, A., et al. (2013). Atmospheric mercury inputs in montane soils increase with elevation: evidence from mercury isotope signatures. Scientific Reports, 3(3322), 1-8.

Zhou, Q. F., Zhang, J. B., Fu, J. J., Shi, J. B., \& Jiang, G. B. (2008). Biomonitoring: An appealing tool for assessment of metal pollution in the aquatic ecosystem. Analytica Chimica Acta, 606(2), 135-150.

Zhu, Y. J., Zhang, Y. Q., Liu, M., Chen, L. G., He, Q. S., Ye, Z. X., \& Sun, J. R. (2014). Distribution and pollution assessment of the mercury in soils of Tibet. Ecology and Environmental Sciences, 23(9), 1487-1491. 